\title{
06 INJURIES BY INTERPERSONAL VIOLENCE IN EMERGENCY ROOMS OF EIGHT HOSPITALS OF THE MINISTRY OF HEALTH, EL SALVADOR, 2010
}

doi:10.1136/injuryprev-2012-040590j.6

${ }^{1}$ Garcia Silvia, ${ }^{2}$ Pereira José, ${ }^{3}$ Nolasco Ulises. ${ }^{1}$ Ministry of Health, Col. Los Andes, Calle Principal No.80, San Marcos, San Salvador, El Salvador, Centro América; ${ }^{2} A B T$ Associates; NOLASCO Ulises; ${ }^{3}$ ABT Associates

Background In El Salvador, interpersonal violence is a major problem for public health which causes injuries, disabilities, and deaths, affecting legal medical services and rehabilitation, which lead to an incalculable human suffering, affecting individuals, families, communities and society in general.

Objective To describe the characteristics of injured by interpersonal violence attended in emergency rooms of eight national hospitals of the Ministry of Health.

Material and Methods Review injury surveillance system database of patients attended in emergency rooms of eight hospitals, from 1 January to 31 December. 2010. Analysis of data was done by Excel 2007. Variables analysed: Hospital, attended, hospitalised, department of the event, year, month, hour, sex, age, occupation, mechanism, intentionality, activity, severity, destiny and type of treatment.

Results 4.301 cases attended by injuries due to interpersonal violence, $89 \%$ they proceed of three departments of the country, being registered the most in January, March and May. The most affected group of age was from 20 to 39 years, with predominance of men (78\%), being the most frequent occupation in over 15 years: Students $(22 \%)$, housekeepers $(20 \%)$ and merchants $(16 \%)$. The greater hours of occurrence were from 6 to $17 \mathrm{~h}(63 \%)$. The lead mechanism was physical force/blunt objects (62\%). The most frequent activity when the injuries occurred was recreation/resting (27\%). The majority of injuries according the severity they were light (61\%), with ambulatory treatment in the majority of cases (75\%).

Significance/Contribution to the Field These results improve our understanding of the characteristics of interpersonal violence-related injuries in El Salvador. 